\title{
Ionospheric response to the sustained high geomagnetic activity during the March '89 great storm
}

\author{
J. J. Sojka and R. W. Schunk \\ Center for Atmospheric and Space Sciences, Utah State University, Logan \\ W. F. Denig \\ PL/GPSP, Phillips Laboratory Air Force Materials Command, Hanscom Air Force Base, Massachusetts
}

\begin{abstract}
A simulation was conducted to model the high-latitude ionospheric response to the sustained level of high geomagnetic activity for the great magnetic storm period of March 13-14, 1989. The geomagnetic and solar activity indices and the DMSP F8 and F9 satellite data for particle precipitation and high-latitude convection were used as inputs to a time-dependent ionospheric model (TDIM). The results of the TDIM were compared to both DMSP plasma density data and ground-based total electron content (TEC) measurements for the great storm period as well as with earlier storm observations. The comparisons showed that the overall structure of the high-latitude ionosphere was dominated by an increased convection speed within the polar cap that led to increased ion temperatures. In turn, this enhanced the $\mathrm{NO}^{+}$density, raised the atomic-tomolecular ion transition height to over $300 \mathrm{~km}$, decreased $N_{m} F_{2}$, increased $h_{m} F_{2}$, and in places either increased $n_{e}$ at $800 \mathrm{~km}$ or slightly decreased it. The morphology of the ionosphere under these extreme conditions was considerably different than that modeled for less disturbed intervals. These differences included the character of the dayside tongue of ionization that no longer extended deep into the polar cap. Instead, as a result of the ion heating and consequent reduction in $N_{m} F_{2}$, a large polar hole occupied much of the polar region. This polar hole extended beyond the auroral oval and merged with the night sector midlatitude trough. The limitations associated with the applicability of the TDIM to the geomagnetic conditions present on March 13 and 14 are discussed. The primary limitations of the TDIM derive from the limited temporal resolution of the model input parameters and the lack of a suitably dynamic thermospheric specification for the great storm conditions. These limitations lead to midlatitude ionospheric storm phases that do not follow those observed.
\end{abstract}

\section{Introduction}

Time-dependent ionospheric models have made remarkable progress over the last decade in quantifying many of the physical processes occurring within the polar regions. They also have been very successful in describing the large-scale features of the high-latitude ionosphere (see review by Sojka [1989]). Favorable comparisons have been made between the model predictions and measured data under a variety of solar and geomagnetic conditions that describe both the steady state characteristics and the dynamic response of the ionosphere. Such comparisons are important in validating models currently being developed as space-weather forecast tools. However, to date, these comparisons have been limited to activity levels well below the geomagnetic conditions that prevail during great geomagnetic storms, such as the one that occurred on March 13-14, 1989. Although great storms are rare, they have profound effects in both space and on the ground when they do occur [Allen et al., 1989].

The midlatitude $F$ region storm response to auroral energy inputs is well understood. Rishbeth [1975] reviewed the

Copyright 1994 by the American Geophysical Union.

Paper number 94JA01765.

0148-0227/94/94JA-01765\$05.00 various mechanisms, especially those dependent upon the thermosphere's storm response. Fuller-Rowell et al. [1991] demonstrated, using a three-dimensional thermosphereionosphere model, that indeed the midlatitude ionospheric response can be simulated. The thermospheric changes are in the form of composition changes, enhanced temperatures, and enhanced winds. These studies found that the midlatitude storm changes are critically dependent on an accurate prescription of the spatial and temporal distributions of the storm energy inputs.

In this study we used the available ionospheric and geomagnetic specification data for the March 1989 great storm in order to test the time-dependent ionospheric model (TDIM) of Schunk [1988, and references therein] under extreme geomagnetic conditions. Although an earlier version of the TDIM was used to study the temporal response of the ionosphere to an isolated geomagnetic substorm of moderate intensity [Sojka and Schunk, 1983], the primary interests in the present case were the temporal evolution and steady state convergence of the model for a sustained level of severe geomagnetic activity, such as that present during great magnetic storms.

In the following two sections we present an overview of the geophysical conditions that prevailed during the great storm of March 1989 and describe the TDIM and its inputs. Section 4 presents the results of the model in "standard" ionospheric 
parameters and contrasts the findings to previously published work as well as to those observed during this storm. The discussion and conclusion sections contain an assessment of the model's performance under these extreme conditions and highlight its strengths and weaknesses as well as presenting new polar ionospheric results.

\section{The March 1989 Great Magnetic Storm}

The great magnetic storm of March 1989 occurred near the peak of sunspot cycle 22 and within a period, March 6 to 19 , that included a number of large solar flares from the region 5395 sunspot group. This elevated solar activity caused a variety of geophysical and societal effects, many of which have been documented by Allen et al. [1989]. The solar flare responsible for the March 13-14 great storm was a class $\mathrm{X} 4.5 / 3 \mathrm{~B}$ (N32, E22) flare that erupted on March 10 [Cliver et al., 1992]. Closer to the Earth, the magnetic storm began as a sudden storm commencement (ssc) at 0128 UT on March 13, and this was followed later that same day by a second ssc at 0747 UT. On the basis of a consideration of commonly used geophysical indices, this storm ranked as one of the most magnetically disturbed periods ever recorded [Allen et al., 1989].

Great magnetic storms are defined as periods of enhanced ring currents having $D$ st depressions below -250 nT [Tsurutani et al., 1992]. For the interval of interest here the measured Dst steadily decreased throughout March 13, reaching a level of $-600 \mathrm{nT}$ near the start of March 14. Changes in the ionosphere and thermosphere during magnetic storms are in response to the changes in auroral precipitation and magnetospheric convection that are statistically related to the $A E$ and $K p$ indices rather than the Dst index. Plotted in Figure 1 are the 3-

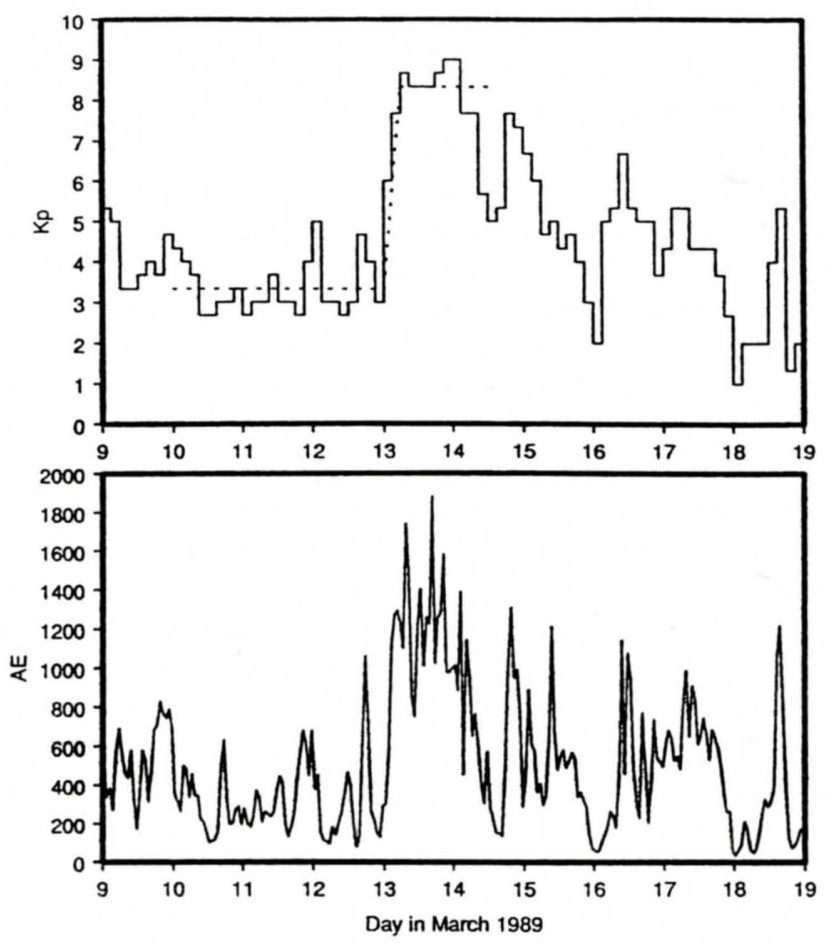

Figure 1. (Top panel) $K p$ and (bottom panel) $A E$ variations for a 10-day period about the great storm of March 13, 1989. The dashed line represents the modeled storm variation of $K p$. hour $K p$ and the 1-hour $A E$ indices for the March 1989 storm period [Coffey, 1989]. The $K p$ index during the first few hours of day 72 (March 13) increased rapidly from an average disturbance level of $3+$ to a sustained level of $8+$ to 9 . Similarly, the $A E$ index showed a rapid increase following the initial ssc on March 13 to a maximum level exceeding $1000 \mathrm{nT}$ after only a few hours. Although the $K p$ and $A E$ indices appeared to saturate after the initial change, Allen et al. [1989] noted that variations in the location of the auroral zone may have adversely affected the magnetic sampling by the reference ground sites.

The ionospheric effects of the March 13-14 storm have been discussed by a number of authors [Allen et al., 1989; Denig et al., 1989; Greenspan et al., 1991; Batista et al., 1991; Rich and Denig, 1992]. For the purposes of the present paper, we limit our attention to the high latitude region that includes the auroral zones and polar caps. In Figure 2 we plot the DMSP. derived equivalent midnight auroral boundary index and the polar cap potential for the period March 9-19 [Rich and Denig, 1992]. These satellite data indicate that throughout the duration of the storm period the low-latitude boundary of the auroral zones was well equatorward of the prestorm and poststorm locations. Similarly, the average polar cap potential during the storm was much larger than that at most other times. The most rapid consistent changes in these parameters occurred during the first few hours following the initial ssc on March 13, although the maximum excursions occurred well after this initial period. For example, a maximum potential of $230 \mathrm{kV}$ was measured at 1200 UT on March 13 and the minimum location for the equivalent midnight boundary was $40^{\circ}$ magnetic latitude (MLAT) at 0100 UT on March 14.

There are no interplanetary magnetic field (IMF) and solar wind data available for the initial day of the storm, March 13. However, it is well known that there is a strong correlation between the occurrence of great geomagnetic storms and IMF $B_{z}$ southward conditions [Burton, 1975; Crooker et al., 1992]. Furthermore, the measured potentials contained within the morningside and eveningside convection cells throughout the storm period were fairly well balanced [Rich and Denig, 1992]. This fact suggests that the IMF $B_{y}$ component was small, although separate ground measurements from Sondrestrom indicate that the drifts within the local noon sector near 1500 UT on March 13 were eastward in accordance with a negative IMF $B_{y}$ component (O. de la Beaujardiere, private communication, 1991). In our modeling, we assumed that for March 13 the IMF was southward with a $B_{y}$ component that was weak and negative at times.

\section{Time-Dependent Ionospheric Model (TDIM)}

The basis of the TDIM is the midlatitude, multi-ion model of Schunk and Walker [1973]. In this original model the timedependent ion continuity and momentum equations were solved as functions of altitude for corotating plasma flux tubes including diurnal variations and all relevant $E$ and $F$ region processes. The development of the TDIM has evolved as the physical mechanisms have become better understood and the computational techniques have improved. The extension of the TDIM to high latitudes was done by including the effects of plasma convection and auroral particle precipitation. The model now also includes the ion and electron energy equations so that the temperatures for the ions and electrons are 


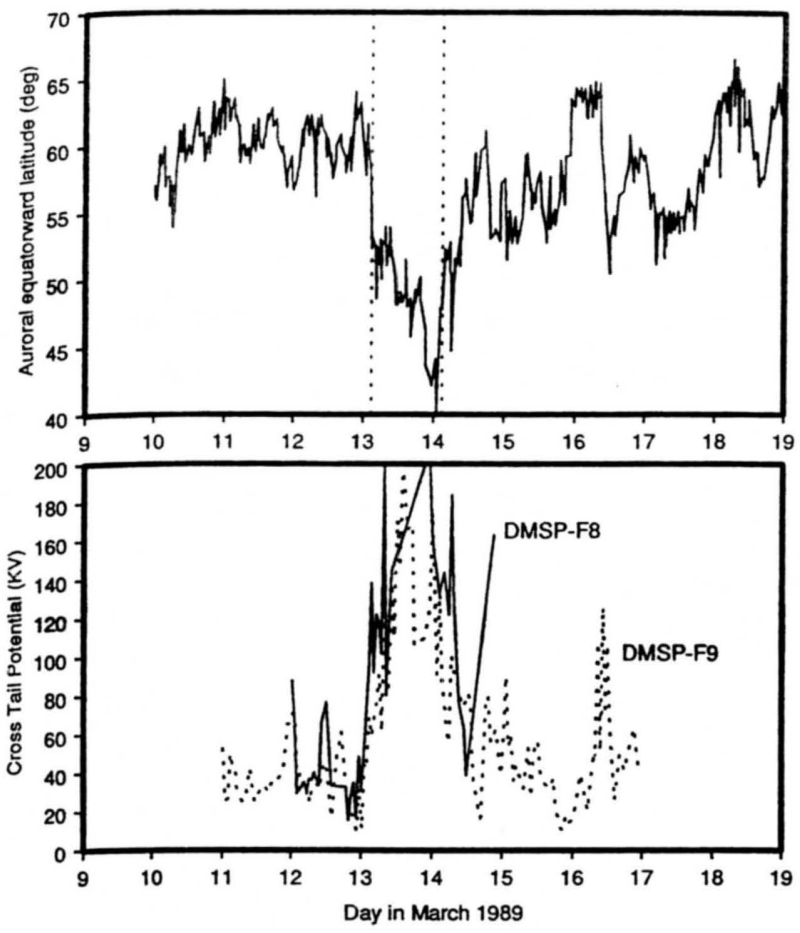

Figure 2. (Top panel) auroral equatorward latitude and (bottom panel) cross-tail potential variations for a 10-day period about the great storm of March 13, 1989. Both parameters were obtained from the DMSP F8 and F9 satellites.

rigorously calculated between 120 and $1000 \mathrm{~km}$. The physical basis and historical development of the TDIM model have been reviewed by Schunk [1988, and references therein], while the numerous comparisons of the TDIM with observations have been reviewed by Sojka [1989]. These papers also provide detailed specifications of the high-latitude ionosphere under various solar and geomagnetic conditions.

Since the electron densities calculated by the model will be compared with observations at $840 \mathrm{~km}$, our topside boundary condition is important. The model does not specify a topside boundary condition for the electron density $\left(\mathrm{O}^{+}\right)$, but instead specifies an electron flux. This time-dependent electron flux through the upper boundary is calculated with allowance for scale height changes in association with $T_{e}$ and $T_{i}$ changes. This allows the ionosphere to "breath" [cf. Schunk, 1988]. Thus the modeled electron density at $840 \mathrm{~km}$ is able to vary according to the storm time ionospheric inputs. For the electron energy equation the topside boundary condition is in the form of a specified heat flux at $800 \mathrm{~km}$. In general, this value is unknown, and hence a value was adopted (see below).

For this great storm simulation the TDIM was configured in a storm mode that was similar to an earlier analysis by Sojka and Schunk [1983]. In this mode the inputs to the TDIM are changed with UT to simulate the storm profile. Note, however, that in the Sojka and Schunk [1983] study the emphasis was on the transient response of the ionosphere to a short-lived substorm of moderate intensity, whereas in this study the emphasis is on the persistent and intense character of a great storm.

The time-dependent inputs used for the great storm profile were keyed to a simulated $K p$ index for March 13, 1989 and adjusted using supporting data from the DMSP satellites.
Starting with a $K p=3+$ at $0000 \mathrm{UT}$, the activity index was linearly increased to a $K p$ level of $8+$ at 0600 UT and thereafter maintained at this extreme level until the end of the model run at 2400 UT. This adopted $K p$ variation is shown in Figure 1 by the dashed line. The convection electric field, the auroral particle precipitation, and the $A p$ index were all coupled to this $K p$ variation. This variation was also used to determine thermospheric (that is, neutral density, wind, and temperature) storm responses, which were introduced through the $A p$ variation according to the MSIS-86 thermosphere model [Hedin, 1987] and HWM90 wind model [Hedin et al., 1991]. The magnitude of the polar-cap potential $\left(\phi_{\mathrm{pc}}\right)$ was initially determined using the empirical relationship, $\phi_{\mathrm{pc}}=(20+14 K p)$ $\mathrm{kV}$ [Sojka et al., 1979] and then modified in accordance with the DMSP-F8 potential calculations. A Heppner and Maynard [1987] model A convection pattern for the northern hemisphere was considered as the most consistent with the inferred IMF orientation. Similarly, patterns of auroral particle precipitation were determined using the $K p>6$ statistical map of Hardy et al [1985], adjusted to the DMSP F8 and F9 auroral boundaries.

In addition to these storm variations there were several other input parameters that were held constant throughout the storm interval. These fixed parameters were the solar EUV spectrum and the magnetospheric electron heat flux. For the great storm conditions a solar maximum EUV input spectrum, represented by an $F_{10.7} \mathrm{~cm}$ radio flux of $210 \times 10^{-15} \mathrm{~W} \mathrm{~m}^{-2}$, was used. A downward electron heat flux at $800 \mathrm{~km}$ of $10^{10} \mathrm{eV} \mathrm{cm} \mathrm{cm}^{-2}$ $\mathrm{s}^{-1}$ was used as the top boundary condition for the electron energy equation [Schunk et al., 1986].

\section{Storm Results}

\subsection{Great Storm Time-Dependent Ionospheric Model}

The TDIM simulation for the March 1989 great storm produced an extensive numerical database of ionospheric constituent densities and temperatures on a universal time (UT), magnetic latitude (MLAT), magnetic local time (MLT), and altitude grid. These model data were binned at 15 -min UT intervals throughout the evolution of the storm simulation for March 13 and were used to derive a number of parameters of physical interest. Plates 1 and 2 show the simulation results for the great storm interval, with the modeled parameters defined on the left and the UT at the top. The results are displayed on MLAT-MLT polar coordinate grids for northern latitudes above $40^{\circ}$ MLAT with magnetic noon located at the top of each panel.

The time "snapshots" of selected ionospheric parameters displayed in Plates 1 and 2 include, respectively, the $F_{2}$ region peak densities $\left(N_{m} F_{2}\right)$ and heights $\left(h_{m} F_{2}\right)$, the electron densities at 148 and $800 \mathrm{~km}$, the ion temperatures at $204 \mathrm{~km}$, the molecular-to-atomic transition heights, the $\mathrm{n}\left[\mathrm{O}^{+}\right]-$to- $n_{e}$ ratios at $300 \mathrm{~km}$, and the distribution of the ionospheric total electron content (TEC). Some of these panels were chosen to highlight certain physical aspects of the ionospheric response to the great storm, while others were chosen to facilitate comparison with existing ionospheric data. For example, ionospheric modifications are generally described in terms of changes in $N_{m} F_{2}$ and $h_{m} F_{2}$, whereas the $n_{e}(800 \mathrm{~km})$ and TEC calculations are readily comparable to available satellite and ground-based data. 


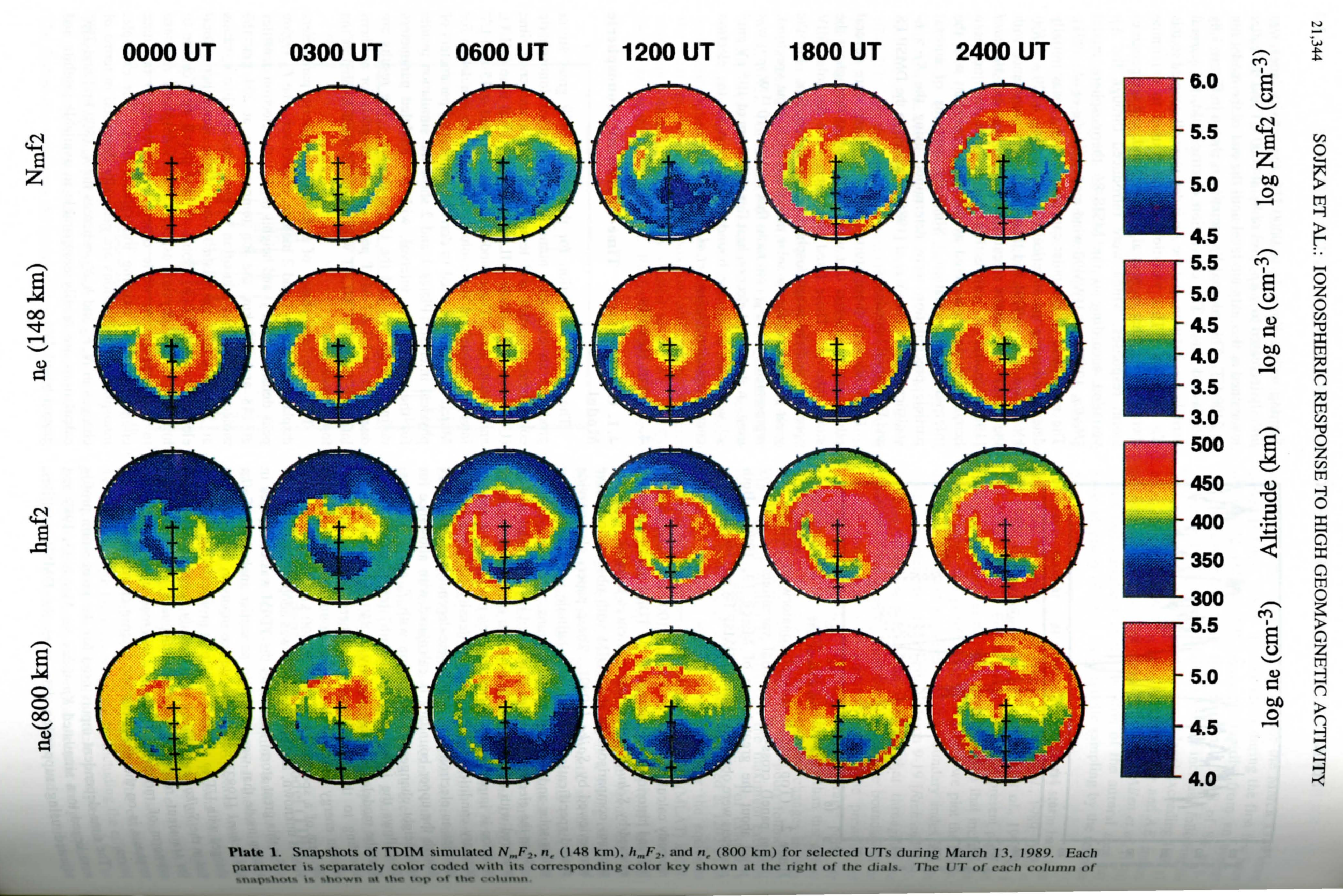




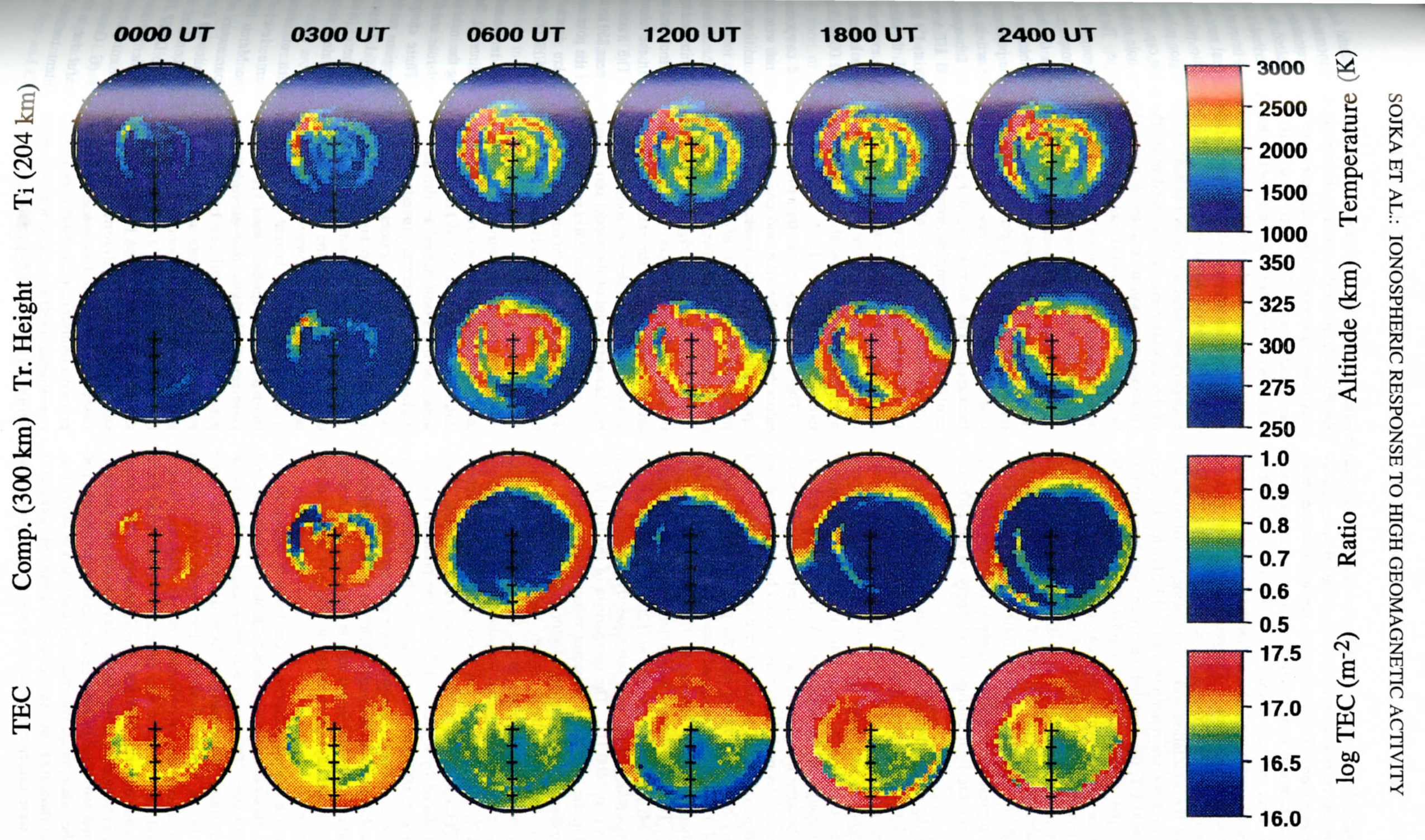

Plate 2. Snapshots of TDIM simulated Ti $(204 \mathrm{~km})$, transition height, ion composition at $300 \mathrm{~km}$, and TEC for selected UTs during March 13, 1989. The format is the same as for Plate 1. 
The principal ionospheric model responses to the great storm inputs were modifications in the local plasma density and ion composition. The ionospheric density structures were considered in terms of their positions relative to the polar cap, the auroral zone, and well-known convection features, such as the "tongue of ionization," the midlatitude trough, the polar hole, and localized hot spots. The geomagnetic activity level systematically increased from a $K p=3$ to $8+$ during the first six hours of the simulation and then remained constant at the very high level for the remainder of the 13 March. Between 0000 and $0600 \mathrm{UT}$, the modeled ionosphere was responsive to changes in the activity level and solar illumination of the northern polar region, while only changes in the location of the solar terminator influenced the model after 0600 UT. Relative to this latter point, it is instructive to compare the model results at the start and end of the simulation, which correspond to similar solar illumination conditions. Reference to prestorm conditions apply to the 0000 .UT model patterns, while the final configurations apply to the 2400 UT results.

The high-latitude patterns for $N_{m} F_{2}$ show the evolution of a nightside, density-depletion region during the course of the great storm. At the start of the storm period, there was a welldefined tongue of ionization that stretched from the nominal location of the dayside cusp into the polar cap and a midlatitude trough on the nightside. As the storm progressed, the tongue became less distinct and localized in the afternoonevening sector. Its peak $N_{m} F_{2}$ was reduced by a factor of two from prestorm values. The mid-latitude trough merged with a large density hole that formed near the pole. Minimum peakdensities of $3 \times 10^{4} \mathrm{~cm}^{-3}$ occurred near 1200 UT in the hole, with persistent effects lasting to the end of the storm simulation. The large-density hole extended down to latitudes below $40^{\circ}$ MLAT near midnight at $1200 \mathrm{UT}$, although the equatorial boundary of the hole subsequently moved poleward to $55^{\circ} \mathrm{MLAT}$ at $2400 \mathrm{UT}$. The comparison of the final $N_{m} F_{2}$ values within the hole to the prestorm values indicates that the $F_{2}$ peak densities were reduced by a factor of about 5 .

Evidence for ionospheric storm variations were also manifested in the model values for $n_{e}(800 \mathrm{~km})$ and the TEC. The nightside region of depleted densities at 2400 UT, relative to $0000 \mathrm{UT}$, was apparent in these physical parameters. Minimum TECs in the hole were on the order of several times $10^{16} \mathrm{~m}^{-2}$, reduced by a factor of 3 from the prestorm values. Similarly, the $n_{e}(800 \mathrm{~km})$ were reduced on the nightside by up to a factor of 5. Closer to the pole, the variation of the dayside densities at $800 \mathrm{~km}$ was distinctly different from the variation in $N_{m} F_{2}$, with $n_{e}(800 \mathrm{~km})$ larger during the storm than at 0000 UT. However, the dayside variation in TEC was similar to the $N_{m} F_{2}$ variation.

The electron density patterns in the lower $F$ region at 148 $\mathrm{km}$ showed no evidence of the density depletion region present at higher altitudes. This result was not unexpected because at this low altitude chemical processes dominate and ionic recombination is rapid. However, for the purposes of this storm simulation, the distribution of $n_{e}(148 \mathrm{~km})$ was a sensitive indicator of local ion production from solar EUV radiation and auroral particle precipitation. The solar terminator, indicated by a decreasing dayside density gradient, had a diurnal variation in latitude that maximized near 1700 UT. On the other hand, the characteristics of the auroral $n_{e}$ $(148 \mathrm{~km})$, indicated by the circular band of enhanced ionization, were directly responsive to the storm inputs. The auroral precipitation pattern was continuously updated during the first 6 hours of the storm as the activity level increased and was then maintained at the highest level for the remainder of the simulation. The increased activity resulted in an equatorward expansion of the auroral zone, as described by the model of Hardy et al. [1985]. During the first six hours of the simulation, the low-latitude boundary of the auroral zone near midnight moved equatorward by $10^{\circ}$, while the poleward boundary remained relatively unchanged. The region poleward of the auroral zone was assumed to be the polar cap. These characteristics indicate that the $F$ region density hole included both the polar cap and the nightside auroral zone. The hole also obscured the location of the mid-latitude trough on the eveningside that was apparent in the prestorm ionosphere.

The storm also caused dramatic changes in the height distribution of the $F_{2}$ peak as well as in the distribution of the ionospheric transition heights. The $h_{m} F_{2}$ near the pole rapidly rose during the first 6 hours of the storm as the activity level increased. The distribution of $F_{2}$ peak heights subsequently evolved into a complex morphology at 2400 UT which, nevertheless, had vestiges of the pattern that existed at 0000 UT. Comparing the patterns at 0000 and 2400 UT, the altitude of the $F_{2}$ peak generally increased, except in the eveningside midlatitude trough. In the central portion of the polar cap, the $h_{m} F_{2}$ rose from a nominal altitude of $425 \mathrm{~km}$ at $0000 \mathrm{UT}$ to over $500 \mathrm{~km}$ at $2400 \mathrm{UT}$.

The differences in the transition heights and composition ratios between the start and end of the model run were also appreciable. For the moderately disturbed conditions that prevailed at the start of the simulation, the ionospheric composition at $300 \mathrm{~km}$ was almost exclusively $\mathrm{O}^{+}$. Similarly, the range of transition heights at 0000 UT was limited and lay between 250 and $275 \mathrm{~km}$. As the activity level increased, so did the variations in the transition height and in the relative composition of molecular ions at $300 \mathrm{~km}$. The transition heights at the end of the model run varied from near $250 \mathrm{~km}$ in the sunlit ionosphere to $350 \mathrm{~km}$ in the center of the polar cap. The corresponding composition ratios at $300 \mathrm{~km}$ decreased during the course of the storm, falling to below $50 \% \mathrm{O}^{+}$after 1200 UT.

Another interesting variation concerns the ion temperature at $204 \mathrm{~km}$ during the early part of the great storm interval. The dominant changes in $T_{i}(204 \mathrm{~km})$ occurred during the initial six hours of the storm period as the activity level rose and the high-latitude convection speeds increased. These changes resulted in elevated $T_{i}$ values in both the polar regions and the auroral zone that were over $1000^{\circ} \mathrm{K}$ hotter at 1200 UT than at the start of the simulation. Following these initial temperature changes, the ion temperatures remained fairly constant for the rest of the storm simulation.

This TDIM simulation provided a wealth of unique ionospheric response data for the extreme level of geomagnetic activity that prevailed during the March 1989 great storm. Comparisons between selected parameters and available ionospheric data are discussed in the following three sub sections. These model-data comparisons consisted of topside plasma density data at $840 \mathrm{~km}$ from the DMSP F8 satellite and ground-based TEC data as well as earlier published storm observations. Unfortunately, attempts to compare our model results with ionosonde measurements (G. Crowley, private communication, 1992) were unsuccessful due to the operational ineffectiveness of this measurement technique during this period of high geomagnetic activity. 


\subsection{Prior Polar Ionospheric Storm Observations}

Midlatitude ionospheric storm effects have been extensively studied and modeled. Their seasonal, as well as longitudinal (UT) phase of the storm onset, dependencies are well appreciated [Rishbeth, 1975; Fuller-Rowell et al., 1991; Foster, 1993]. However, in contrast, the polar ionospheric storm effects are not well established and little modeling has been done. Only a few papers have been published showing polar ionosonde observations during storms. This lack of ionosonde data is due mainly to problems associated with $D$ region absorption events, which make $F$ region observations difficult, if not impossible, during storms.

Duncan [1969] used a global distribution of ionosondes, of which three were in the northern polar cap, to study the $F$ region storm behavior. From his bottomside soundings data he was able to show that during disturbed activity $N_{m} F_{2}$ in the polar cap is decreased by up to a factor of 2 . This result is consistent with the Plate $1 N_{m} F_{2}$ simulations. Indeed, the up to a factor of 2 reduction in peak density is numerically similar to that shown in Plate 1 when comparing 0000 UT (quiet) with 2400 UT (storm) times.

The Alouette 1 topside sounder data have provided storm observations in the polar cap. Nishida [1967] compared Alouette 1 topside sounder data from the $F$ region peak to an altitude of $1000 \mathrm{~km}$ in the polar noon-midnight orbit plane for the storm of September 21-23, 1963, with observations on quiet days. This storm was an equinox storm, much like the storm in this study, that reached a $K p$ of $9^{-}$, which is also similar to our storm. Nishida found that in the midnight sector of the polar cap the topside $F$ region density was enhanced by up to a factor of 2 during the storm. The electron density in the noon sector of the polar cap and $N_{m} F_{2}$ in general tended to be reduced during the storm. In Plate 1 the $N_{m} F_{2}$ variation shows a similar trend (prestorm is 0000 UT and fully developed storm is $2400 \mathrm{UT}$ ). The day sector polar cap electron density at 800 $\mathrm{km}$ is enhanced, whereas in the one storm study of Nishida the density in the night sector of the polar cap was enhanced.

A more extensive Alouette 1 topside sounder study of storms was carried out by Sato and Chan [1969]. They used 14 storm intervals in the 1962-1963 winter and equinox periods and found both enhancements and depletions in the polar ionosphere. Unfortunately, they combined an equal number of summer and winter storm cases to obtain a general finding. Their result is similar to that found by Nishida [1967], namely that the nightside of the polar cap tends to show electron density enhancements at high altitudes, whereas the $F$ region peak and dayside polar cap densities tend to be reduced. Again, the $N_{m} F_{2}$ trends are consistent with the TDIM model results, which arise from a combination of physical processes. These processes are enhanced plasma temperatures in the polar cap which increase the topside scale heights (see $T_{i}$ at $204 \mathrm{~km}$ in Plate 1), neutral wind (and $\mathbf{E} \times \mathbf{B}$ ) induced downward (upward) drifts in the noon sector of the polar cap which lower (raising) the $F$ layer and then it is raised (lowering) in the night sector polar cap (see $h_{m} F_{2}$ in Plate 1), and enhanced loss rates in the heated $F$ region as $\mathrm{O}^{+}$is converted into $\mathrm{NO}^{+}$(see composition and transition height in Plate 1). All three processes are at work and significant, hence demonstrating the need for a complex time-dependent computer model. At $800 \mathrm{~km}$, the Alouette 1 observations are suggestive of a dayside depletion and nightside enhancement in the polar cap. This is different than that found in this study (Plate $1, n_{e}$ at $800 \mathrm{~km}$ ). However, the Sato and Chan [1969] study that highlights this trend was based on combined winter and summer data to obtain the daytime depletion, which is a well-defined sunlight ionospheric response to storms. Hence, this issue will need further analysis and observational data before being resolved.

\subsection{Topside Plasma Density Observations}

Plasma density measurements near $840 \mathrm{~km}$ were made by the DMSP satellites $F 8$ and $F 9$, for the great storm period of March 1989. Using DMSP data from this storm period, Greenspan et al. [1991] have reported on the anomalous behavior of the electron density in a geographically limited region around the equator on March 13-14, 1989. However, the DMSP densities presented in this section and designated as $n_{e}(840 \mathrm{~km})$ were high-latitude measurements, and these have not been reported on previously. Note that the differences in $n_{e}$ associated with altitude differences between the model upper boundary of 800 $\mathrm{km}$ and the satellite measurements made at $840 \mathrm{~km}$ were assumed to be of minor significance.

In section 3 the model topside boundary condition was discussed. As noted, the ionosphere is allowed to breathe, but no plasma is allowed to escape. Even during a major storm the electric fields and particle precipitation levels are not expected to produce heating to a level that would invalidate this assumption. However, the possibility of ionospheric energization sources other than transport mechanisms may locally affect the validity of the model in general. At this time, such effects have not been quantified and, hence, are not considered.

The DMSP satellite network during March 1989 consisted of two, Sun-synchronous satellites in $98.7^{\circ}$ inclination orbits near altitudes of $840 \mathrm{~km}$. The F8 and F9 satellites were in approximate dawn-to-dusk and noon-to-midnight orbits, respectively, with each satellite traversing the northern polar region about once every $100 \mathrm{~min}$. The subsatellite orbital tracks for selected northern polar crossings by the DMSP F8 satellite for March 13, 1989, are plotted in Figure 3. Detailed descriptions of the DMSP satellites and the relevant instrumentation have been presented elsewhere and are not repeated here except to note that the $n_{e}(840 \mathrm{~km})$ measurements discussed below were made using the total ion density trap of the thermal plasma instrument [Greenspan et al., 1986].

The DMSP $n_{e}(840 \mathrm{~km})$ data for March 13, 1989 are presented in Figures 4 for F8. The density data for F8 are

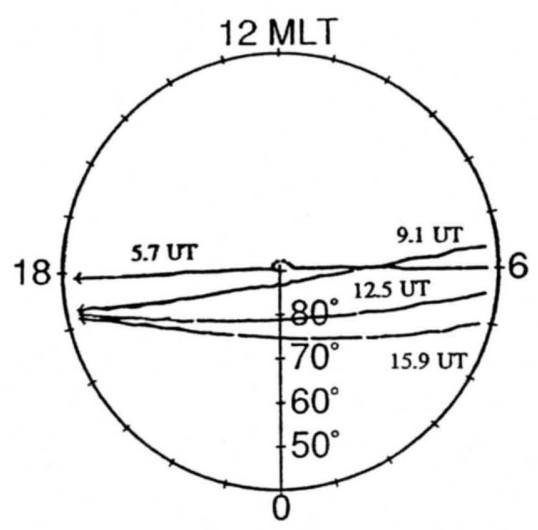

Figure 3. Four selected DMSP F8 orbital tracks in the northern hemisphere plotted in a magnetic local timeinvariant latitude polar coordinate system. Each orbital track is labeled with a decimal universal time (UT) hour. 

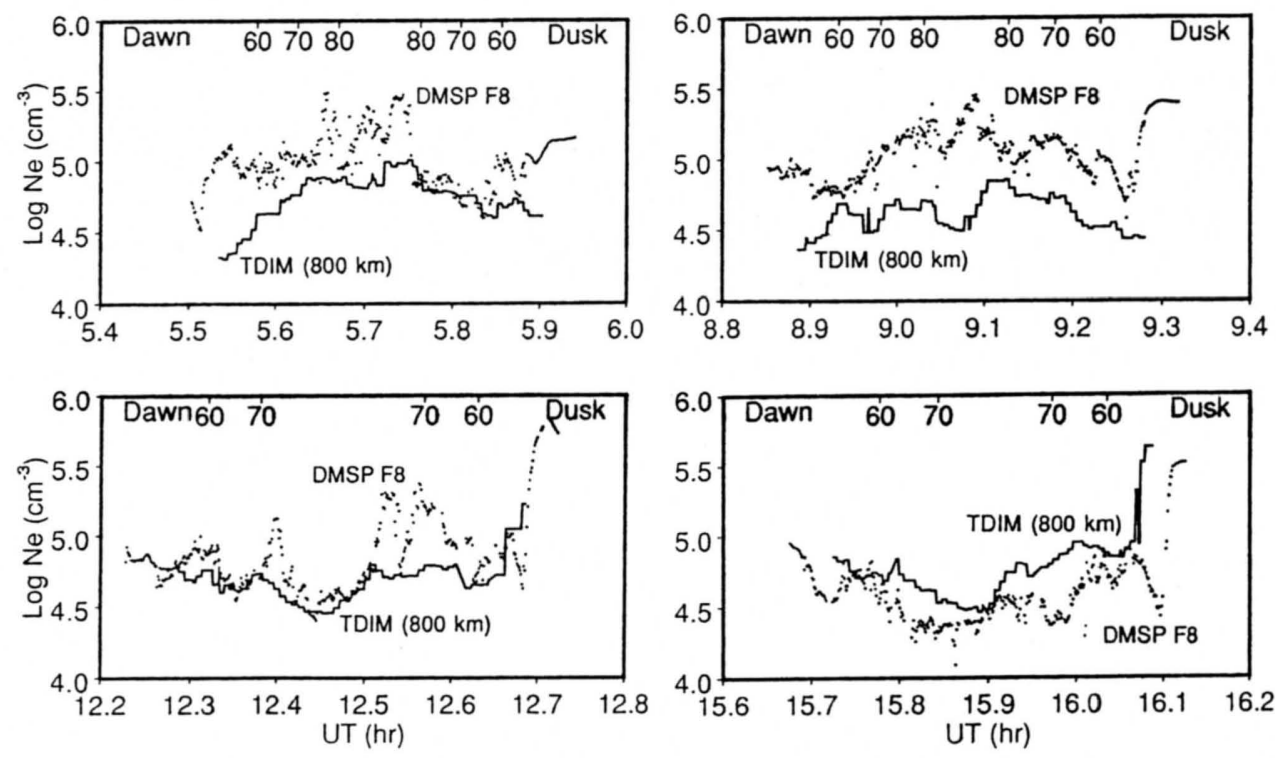

Figure 4. DMSP F8 electron densities (dots) and corresponding TDIM electron densities (lines) for the four orbits shown in Figure 3. Electron densities $\left(\log _{10}\right)$ are plotted as a function of decimal UT (hour) with key invariant latitudes labeled at the top of each panel.

plotted versus UT (decimal hours) with the magnetic pole near the center and the dawn (dusk) local time sector on the left (right), as indicated. The satellite data are drawn as dotted curves, and the corresponding solid lines represent the model predictions for $n_{e}(800 \mathrm{~km})$. In Figure 4, invariant latitudes are labeled at the top of each panel, while the local times are shown in Figure 3.

The $n_{e}(840 \mathrm{~km})$ satellite data in Figure 4 detail the 05001600 UT formation of a mesoscale polar density depletion in response to the increasing level of magnetic activity on March 13. Superimposed on this mesoscale depletion are numerous small-scale density enhancements (factors of 2 to 4 ). Between 0500 and 0900 UT, the polar cap density was about $10^{5} \mathrm{~cm}^{-3}$, by 1200 UT it had dropped to $4 \times 10^{4} \mathrm{~cm}^{-3}$, and by $1600 \mathrm{UT}$ it had reached $\sim 2 \times 10^{4} \mathrm{~cm}^{-3}$. This trend was reasonably well modeled, as seen in Figure 4 and as is evident in the $N_{m} F_{2}$ trend shown in Plate 1. The small-scale enhancements in $n_{e}$ observed by $F 8$ are different on each pass. This is consistent with the expectation that each enhancement is a localized region of enhanced density that is moving antisunward at the convection speed. During this time, speeds of the order of 1 to $2 \mathrm{~km} / \mathrm{s}$ are typical; hence, in $100 \mathrm{~min}$ (the orbital period) these localized structures would have moved a distance of from 6000 to $12000 \mathrm{~km}$. Such distances are significantly greater than the extent of the polar cap, and hence no correlation between structures observed on successive orbits would be expected.

The DMSP F9 night sector densities are similar to those shown in Figure 4 and to those modeled in Plate 1. Both satellite observations show a marked dusk-night sector density increase at mid-latitudes after about 0900 UT (see F8 observations in Figure 4). This increase is also modeled by the TDIM. However, the exact latitude of the enhancement is not accurately modeled. This latitude is determined entirely by the convection pattern and demarcates the transition from corotational midlatitude flow to either stagnant or auroral plasma flow.

In the DMSP F9 observations a region of enhanced plasma flow was observed for many hours in the prenoon $65^{\circ}-75^{\circ}$ invariant latitude region. However, the magnitude of the convection speed was uncertain since instrumental saturation occurred at $\sim 2500 \mathrm{~m} / \mathrm{s}$. This region was observed repeatedly during the storm and was a persistent feature, and as such, would be a source of intense Joule heating. The consequences of this heating would be enhanced ion temperatures and reduced plasma densities. However, the local time extent of the region and the direction of the enhanced flow were unknown and, consequently, the details of this region could not be rigorously modeled. Therefore it was not surprising that the F9 plasma densities in this region were a factor of 2 to 4 lower than modeled.

\subsection{Total Electron Content Measurements}

Ground-based observations of the TEC were made from several sites on the March 13, 1989. Data corrected for oblique ray paths (i.e., converted to vertical TECs) from three sites will be presented to show the model and observation comparison. These sites are Kennedy $\left(35^{\circ} \mathrm{N}, 300^{\circ} \mathrm{E}, 42^{\circ}\right.$ invariant latitude), Hamilton $\left(45^{\circ} \mathrm{N}, 700^{\circ} \mathrm{E}, 50^{\circ}\right.$ invariant latitude), and Goose Bay $\left(55^{\circ} \mathrm{N}, 320^{\circ} \mathrm{E}, 65^{\circ}\right.$ invariant latitude). Kennedy is located at the equatorward edge of our TDIM simulation domain and is a true midlatitude station, while Hamilton typically lies near the midlatitude trough, but during the most expansive phase of the storm it was in the auroral oval. Goose Bay is an auroral station and remained so throughout the storm.

From ground-based observations the TEC is the path integral of the electron density through the ionosphere, plasmasphere, and magnetosphere to the beacon satellite. For the present study the beacon satellite was located at geosynchronous orbit. The TEC was obtained using the Faraday rotation technique, which has been shown by Titheridge [1972] to be sensitive to electron densities to an altitude of $2500 \mathrm{~km}$. In comparing the observed slant TEC values with the TDIM model calculations, which are vertical TEC values up to $800 \mathrm{~km}$, two points need to be considered. Firstly, the observed slant TEC values are corrected to vertical 
and, secondly, the TEC difference due to the plasma between 800 and $2500 \mathrm{~km}$ needs to be estimated. Considering a worst case scenario of a constant density of $10^{3} \mathrm{~cm}^{-3}$ over this altitude range a TEC of 0.17 TEC units is obtained (1 TEC unit is $10^{16}$ electrons $/ \mathrm{m}^{2}$ ). This is negligible compared to the contribution from the ionosphere below $800 \mathrm{~km}$ (see Plate 2), and we present the observed slant TEC corrected to make it a vertical TEC.

The TEC values as a function of UT on the March 13, 1989, are shown in Figure 5 along with the corresponding TDIM TEC values. These data correspond to the prestorm and expansion periods from 0000 to $0600 \mathrm{UT}$ and to the sustained activity
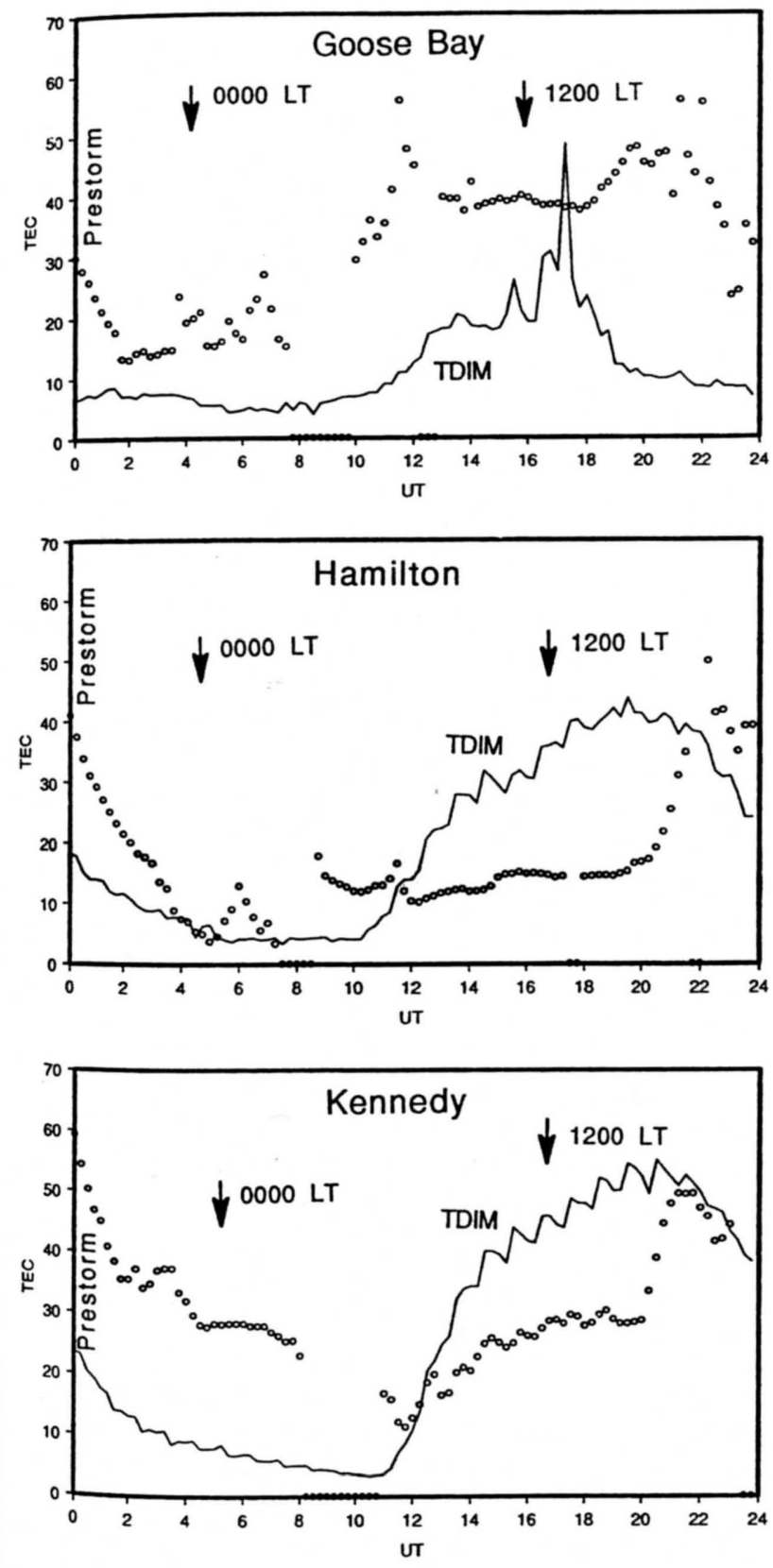

Figure 5. Observed total electron content (TEC) values from (top) Goose Bay, (center) Hamilton, and (bottom) Kennedy shown as circles along with TDIM TEC values (lines). TEC values are in units of $10^{16}$ electrons $/ \mathrm{m}^{2}$. The data are for March 13, 1989. period from 0600 to 2400 UT. For the first few hours the observed TEC are at least twice those obtained from the TDIM. These TEC values are in the late afternoon and reflect a known problem that the ionospheric community is actively working to resolve. Namely, during "solar maximum" conditions, it has been found that dayside $N_{m} F_{2}$ (solar EUV produced ionosphere) values are typically $50 \%$ to a factor of two larger than predicted by physical models. An NSF CEDAR working group, "Problems Related to Ionospheric Modeling and Observations" (PRIMO), is actively and systematically working to resolve this problem. Given that $N_{m} F_{2}$ is lower by a factor of 2 in the TDIM, then the computed TEC is also lower by this amount. By about 0600 UT the storm reached its mean storm value. At this time all three TEC sites were in the midnight sector, and at about this time, data drop outs occurred at all three sites (i.e., TEC $=0$ in Figure 5).

At Goose Bay, which was inside the auroral oval, the 1200 to 2400 UT period shows TEC to be above 30 TEC units. The model, on the other hand, indicates that TEC remains below 20 TEC units with only a brief 2 -hour period above this value. Although this appears as a large discrepancy when viewed in a global prospective, the difference is not that severe since the model shows strong latitudinal gradients in TEC (see Plate 2, bottom row). At 1800 UT, Goose Bay was near magnetic noon. Figure 5 indicates an observed 40 TEC units, while the model is around 25 TEC units. In Plate 2 at 1800 UT, Goose Bay ( $72^{\circ}$ invariant latitude) lies in a red region (25 TEC units); however, immediately equatorward of this region the TEC increases to above 30 TEC units. The location of these gradients depends on the convection pattern. Hence a small overall change in the convection pattern would readily increase or decrease the TDIM TEC for Goose Bay by 10 TEC units.

Around the same UT period, the other two sites (Hamilton and Kennedy) were in the noon sector midlatitude ionosphere. Both show depressed TEC values until about 2000 UT. The ionosphere was experiencing a well-defined "storm negative phase" in that the TEC was reduced from its normal or median value. The TDIM is unable to respond to the storm with a negative phase because the MSIS- 86 atmosphere does not have a storm dependence on the scale of a sustained $K p \quad 8+$ level built into it. After 2000 UT the ionosphere recovered and TEC increased rapidly to its midlatitude late afternoon value. The TDIM with a heated neutral atmosphere is able to reproduce these TEC values.

The TEC comparisons highlight the difficulty of using a climatology-type set of model inputs to represent a dynamic ionosphere. It lacks atmospheric sensitivity to storm phases, which would require a coupled ionosphere-atmosphere model or an empirical atmosphere that has sensitivity to atmospheric changes in composition and UT phase during such large storms. The problem at higher latitudes is faced by all modelers, that is, defining the key inputs (auroral and convection) with adequate spatial and temporal resolutions.

\section{Discussion}

The TDIM storm simulation produced a model ionosphere that was in balance with numerous competing processes. Included in this list of relevant processes were solar and auroral ionization, recombination and other chemical mechanisms, diffusion, and energy transport. An important observation by Rich and Denig [1992] for the great storm of March 1989 was 
that the distribution and magnitudes of the convection electric fields were consistent with the observed level of geomagnetic activity. On the other hand, standard activity indices, such as $K p$ and AE, appeared to have saturated during the March 1989 storm [Allen et al., 1989], in agreement with great storm observations in general [Weimer et al., 1990]. For the March 1989 great storm simulation the measured forcing functions (that is, the observed electric fields and the auroral particle precipitation) were used in the TDIM to model ionospheric responses consistent with the observations. However, as already discussed in section 4.3 , the region of extremely high electric fields in the morning-noon sector could not be modeled because of inadequate knowledge of the extent of this region.

The TDIM storm simulation was primarily concerned with the growth and main phases of a sustained geomagnetic disturbance of significant proportions. During the growth phase the changes in the storm inputs were on time scales of several hours and, hence, were comparable to the response time of the ionosphere near the $F_{2}$ peak [Sojka and Schunk, 1983]. Our prior modeling of ionospheric storm responses only considered relatively rapid temporal variations in the magnetospheric inputs [Sojka and Schunk, 1983, 1984]. In these earlier storm studies the maximum $K p$ was only 5 and that only lasted $11 / 2$ hours. Hence heating effects on the scale observed in this study never materialized. Indeed, in our simulations involving short-lived storms, the electron density was mainly enhanced at the $F$ layer peak and above, and only for a few hours after the storm. For the present storm study the extended growth phase and the sustained high activity level associated with the main phase were more comparable to our previous time-stationary studies with high geomagnetic activity [Sojka et al., 1981b, 1982; Schunk and Sojka, 1982a, b; Schunk et al., 1986].

These earlier time-stationary studies used $K p$ values of 5 for strongly disturbed conditions, while in this storm study a $K p$ of $8^{+}$was used. Compared with the earlier strong convection studies, similar effects are found. However, now the major new effect is that the enhanced $\mathrm{NO}^{+}$densities and recombination rates that are associated with the intense ion heating lead to a large polar hole. In the earlier studies, downward $\mathbf{E} \times \mathbf{B}$ drifts in the night sector of the polar cap were the dominant polar hole mechanism.

The vertical transport of ionospheric plasma can be driven by the aforementioned $|\mathbf{E} \times \mathbf{B}|$ force, by the collisional interaction of the ionosphere with the neutral wind, and by diffusion. The electrodynamic force tends to raise the $F_{2}$ layer on the dayside of the polar cap and to depress the layer on the nightside. The thermospheric wind contributes to the vertical motion, on the other hand, by pushing the plasma down on the dayside and up on the nightside, which is opposite to the effect of the electrodynamic force. Enhanced ionospheric temperatures at low altitudes, whether local or global, tend to increase both the upward ambipolar diffusion of ionospheric plasma and the topside scale heights. As a point of reference, we note that high-latitude plasma drift measurements at 840 $\mathrm{km}$ indicated that the ionospheric vertical motions were mostly upward on the dayside and downward at night. The magnitudes of these vertical drifts were of the order of several hundreds of $\mathrm{m} \mathrm{s}^{-1}$ [Rich and Denig, 1992]. The measured ion drifts in the polar cap for the great storm period were mostly antisunward with speeds of from 1 to $2 \mathrm{~km} \mathrm{~s}^{-1}$, on average [Rich and Denig, 1992]. For the TDIM simulation the convection electric fields in the polar cap were typically 40 $\mathrm{mV} \mathrm{m}^{-1}$, as specified. The calculated downward plasma drifts resulting from the $|\mathbf{E} \times \mathbf{B}|$ force were $\sim 150 \mathrm{~m} \mathrm{~s}^{-1}$ both on the nightside of the polar cap and in the midnight sector of the auroral oval. The corresponding dayside vertical drifts were upward and maximized near $100 \mathrm{~m} \mathrm{~s}^{-1}$ in the postnoon region of strong ion drifts for the "model A" pattern [Heppner and Maynard, 1987].

The neutral wind is also enhanced during active times in the polar regions [McCormac et al., 1987]. The antisunward plasma convection in the polar cap which exceeds $1000 \mathrm{~m} / \mathrm{s}$ leads to a strong antisunward neutral wind flow. McCormac et al. [1987] showed that the wind speeds can reach $800 \mathrm{~m} / \mathrm{s}$ under extremely active conditions. These neutral wind observations have been included in the empirical neutral wind model of Hedin et al. [1991], and this model was used in the storm simulations. This enhanced neutral wind also leads to a vertical induced drift, which normally is opposite to that of the $\mathbf{E} \times \mathbf{B}$ induced vertical drift. In considering this storm, in which sustained high-speed plasma convection was maintained for hours, it is very likely that the neutral wind was driven at high speed in the same direction as the convection, but with a speed that could only reach about one third that of the plasma convection. This is a typical upper limit for the process by which $\mathbf{E} \times \mathbf{B}$ ion drifts can couple to the neutral atmosphere and drive a neutral wind. As a result, the neutral wind induced vertical drifts would be, similarly, one third smaller and in the opposite sense to the $\mathbf{E} \times \mathbf{B}$ vertical induced drift.

Local ion temperature increases in the TDIM simulation were due to ion-neutral frictional heating and auroral particle precipitation. In the auroral zone at $F$ region altitudes the enhanced temperatures caused a diffusive upflow of the thermal ions at speeds of up to $100 \mathrm{~m} \mathrm{~s}^{-1}$. In the nightside auroral zone for the storm simulation, this process only slightly affected the overall downward flow of the ionosphere, which was dominated by the electrodynamic effect. Major increases in $T_{i}$ $(204 \mathrm{~km})$ via the frictional heating mechanism were simulated throughout the high-latitude region; these caused the unique chemistry features that dominated the $F$ peak. The high ion temperatures led to an enhanced conversion of $\mathrm{O}^{+}$into $\mathrm{NO}^{+}$, which in turn led to enhanced loss rates. This is seen as a general increase in the altitude of molecular ion over atomic ion dominance (Plate 2), in the composition being molecular rich $\left(\mathrm{NO}^{+}\right)$at $300 \mathrm{~km}$ over most of the polar cap and auroral regions, and in $h_{m} F_{2}$ being generally higher throughout the polar cap (Plate 1). The latter being a result of the marked increase in the altitude where diffusion takes over from recombination.

An interesting feature of the TDIM storm simulation was the development of ionospheric "hot spots" at high-latitudes. Hot spots appear in Plate 2 (row 1) for $T_{i}(204 \mathrm{~km}$ ) as regions of locally enhanced ion temperatures approaching $3000 \mathrm{~K}$. Ionospheric hot spots form in "localized" regions of large electric fields and imply significant levels of ion-neutral frictional heating in the lower $F$ region [Schunk and Sojka, $1982 b$ ]. However, the modeled hot spots for the great storm simulation were a direct consequence of the "adopted" convection pattern, which may not necessarily represent the actual state of the ionosphere in a localized region during the great storm. In the region of the hot spots, no convection measurements were available and, hence, no definitive conclusions about the existence of the hot spots can be made. However, Rich and Denig [1992] found that, in general, the 
electric fields in the auroral region during the storm were smaller than those obtained from the Heppner-Maynard convection model in the dusk convection cell. Relative to the extreme magnitude of the polar cap potential, they noted that the expanded size of the auroral oval was able to accommodate the modest field strengths observed. These results suggest that the hot spots in the dusk sector may not have existed during the great storm. On the other hand, an extended hot spot probably existed in the prenoon sector between $65^{\circ}-75^{\circ}$ latitude, where the ion drifts (i.e., electric fields) were greater than the saturation limit of the instrument. Since the adopted Heppner-Maynard convection model did not mimic this feature, the TDIM simulation did not predict a localized hot spot in this region.

The trough and midlatitude regions undergo significant changes both in density and the latitudes of their features (see $N_{m} F_{2}$ in Plate 1). Both DMSP observations and the simulations (Figure 4) show a marked low-latitude evening density enhancement. This boundary, a step function in the $n_{e}$ $(800 \mathrm{~km})$ observations, is representative of the demarcation between corotation and trough convection. As shown by both the observations and model, it has become a readily identified feature. During less disturbed and quiet conditions this feature is usually not a marked or unique feature. Hence, under storm conditions, this feature will provide a key observational boundary for the transition from corotational to disturbed plasma flow.

Perhaps the most telling difference between the observations and the TDIM simulation is the Hamilton and Kennedy midlatitude TECs. At both stations a pre-noon TEC depletion, relative to the TDIM simulation, occurred. From the discussions in section 4.3 on TEC, it is clear that under quiet conditions the TDIM TEC would be expected to be lower than the observations around noon. This discrepancy in the dayside midlatitude TECs during the storm could well be associated with the lack of a self-consistent coupling with the neutral atmosphere in our simulations, such that we are not modeling the ionospheric positive and negative storm phases correctly. The prenoon sector is also the one in which the DMSP F9 electric field observations show a region of sustained large electric fields. Since this region is sunlit, the associated large conductivities imply a large source of Joule heating. Such a "local" neutral atmosphere hot spot is not included in the MSIS-86 atmosphere model. Again, the difficulty is that the DMSP F9 satellite shows the presence of such a region, but its longitudinal extent is unknown and hence cannot be readily inputted into neutral atmosphere, ionosphere, or coupled neutral atmosphere-ionosphere models.

Our understanding of the midlatitude ionosphere's response to storms is quite advanced and shows that a coupled thermosphere-ionosphere model driven by a well-defined UT timing of the storm energy input is critical for negative or positive ionosphere response predictions [Rishbeth, 1975; Fuller-Rowell et al., 1991]. The absence of ionosonde data during the storm makes identification of the $F$ layer peak storm phases extremely difficult. In our simulation we have been unable to adequately define the storm input history, which has led in part to the midlatitude TEC observation-model discrepancies.

The electron density observed at high latitudes by DMSP F8 and F9, of which four orbits of F8 data are shown in Figure 4, contains structure on scale sizes of tens to hundreds of kilometers. These features are also not amenable to modeling because of a lack of input resolution, (i.e., convection and precipitation fine structure). The necessary spatial and temporal resolutions would be quite high, since the highlatitude plasma speeds are of the order of 1 to $2 \mathrm{~km} / \mathrm{s}$. In $5 \mathrm{~min}$ at these speeds, plasma structures move distances of 300 to $600 \mathrm{~km}$, which is comparable to or larger than the horizontal dimensions of the structures. Hence measurements would have to be made at a minute time resolution, with spatial resolutions $\leq 100 \mathrm{~km}$, at both midlatitude and high latitude. Auroral imagery has the capability of achieving this resolution for the precipitation, but as yet, no technique has this resolution for observing the convection electric field.

\section{Conclusion}

The fundamental conclusion drawn from these results and comparisons is that the simulation of the great magnetic storm of March 1989 was within the capabilities of the TDIM. During this storm the ionosphere underwent major changes at both midlatitude and high latitude. These changes were attributed primarily to the changes in both the convection electric field and auroral precipitation. However, as discussed, the resulting changes in the neutral atmosphere introduced additional ionospheric modifications. Although the convection and auroral inputs were defined with limited resolution, the ensuing TDIM ionospheric simulation was consistent with the observations of Rich and Denig [1992]. Where specific differences were found, it was possible to reconcile them in view of the uncertainty in the model inputs (convection and precipitation) and the lack of coupling between the neutral atmosphere and ionosphere in our simulation.

The key findings are as follows:

1. In the polar ionosphere the sustained high antisunward convection leads to enhanced ion temperatures that dominate much of the polar $F$ region morphology.

2. As a consequence, molecular ions $\left(\mathrm{NO}^{+}\right)$are dominant to altitudes over $300 \mathrm{~km}$.

3. The enhanced recombination rates lead to enhanced $h_{m} F_{2}$ values and a large-scale polar hole.

4. With enhanced topside scale heights the densities at $800 \mathrm{~km}$ are not reduced by as much as those at the $F$ region peak. Indeed, in some regions of the cap, density increases can be found at $800 \mathrm{~km}$.

5. Because of the high convection speeds, plasma structures (i.e., blobs) would cross the entire polar cap in about 20 to $30 \mathrm{~min}$. This makes identification and tracking of plasma structures in the polar ionosphere very difficult during major magnetic storms.

6. Since Joule heating could not be introduced accurately in the simulated neutral atmosphere, the overall $K p=8^{-}$MSIS86 model produced statistically averaged neutral atmosphere heating. As a consequence, the TDIM at midlatitudes does not produce a realistic sequence of storm phase responses.

The results of our study validate present day ionospheric modeling formulations under extreme geomagnetic disturbance levels. This study, which was based on observed electric fields, used electric field magnitudes that were typically twice as large as those previously used in TDIM simulations. The results also indicate the crucial need for a higher resolution in convection electric field measurements, both spatially and temporally. 
Acknowledgments. This research was supported by NASA grant NAG5-1484 and NSF grant ATM-93-08163 to Utah State University.

The Editor thanks R. G. Roble and S. I. Akasofu for their assistance in evaluating this paper.

\section{References}

Allen, J., H. Sauer, L. Frank, and P. Reiff, Effects of the March 1989 solar activity, Eos Trans. AGU, 70, 1486-1488, 1989.

Batista, I. S., E. R. De Paula, M. A. Abdu, and N. B. Trivedi, Ionospheric effects of the March 13, 1989 magnetic storm at low and equatorial latitudes, J. Geophys. Res., 96, 13,943-13.952, 1991.

Burton, R. K., R. L. McPherron, and C. T. Russell, An empirical relationship between interplanetary conditions and Dst, J. Geophys. Res., 80, 4204-4214, 1975.

Cliver, E. W., N. U. Crooker, and H. V. Cane, The semiannual variation of great geomagnetic storms: Solar sources of great storms, Proc. First SolTip Sym., Liblice, Czechoslovakia, 1991, in press, 1992.

Coffey, H. E., Geomagnetic and solar data, J. Geophys. Res., 94, $10,154,1989$

Crooker, N. U., E. W. Cliver, and B. T. Tsurutani, The semiannual variation of great geomagnetic storms and the postshock RusselMcPherron effect preceding coronal mass ejecta, Geophys. Res. Lett., 19, 429-432, 1992.

Denig, W. F., F. J. Rich, and M. Hairston, A DMSP overview of the March 1989 storm period (abstract), Eos Trans. AGU, 70, 1280, 1989.

Duncan, R. A., $F$ region seasonal and magnetic-storm behavior, $J$. Atmos. Terr. Phys., 31, 59-70, 1969.

Foster, J. C., Storm time plasma transport at middle and high latitudes, $J$. Geophys. Res., 98, 1675-1689, 1993.

Fuller-Rowell, T. J., D. Rees, H. Rishbeth, A. G. Burns, T. L. Killeen, and R. G. Roble, Modeling of composition changes during $F$ region storms: A reassessment, J. Atmos. Terr. Phys., 53, 541-550, 1991.

Greenspan, M. E., P. B. Anderson, and J. M. Pelagatti, Characteristics of the thermal plasma monitor (SSIES) for the Defense Meteorological Satellite Program (DMSP) spacecraft S-8 through S-10, Rep. AFGLTR-86-0227, p. 111, Hanscom Air Force Base, Mass., 1986.

Greenspan, M. E., C. E. Rasmussen, W. J. Burke, and M. A. Abdu, Equatorial density depletions observed at $840 \mathrm{~km}$ during the great magnetic storm of March 1989, J. Geophys. Res., 96, 13,931-13,942, 1991.

Hardy, D. A., M. S. Gussenhoven, and E. Holeman, A statistical model of auroral electron precipitation, J. Geophys. Res., 90, 4229-4248, 1985.

Hedin, A. E., MSIS thermospheric model, J. Geophys. Res., 92, 46494662, 1987.

Hedin, A. E., M. A. Biondi, R. G. Burnside, G. Hernandez, R. M. Johnson, T. L. Killeen, C. Mazaudier, J. W. Meriwether, J. E. Salah, R. J. Sica, R. W. Smith, N. W. Spencer, V. B. Wickwar, and T. S. Virdi, Revised global model of thermosphere winds using satellite and ground-based observations, J. Geophys. Res., 96, 7657-7688, 1991.

Heppner, J. P. and N. C. Maynard, Empirical high-latitude electric field models, J. Geophys. Res., 92, 4467-4489, 1987.

McCormac, F. G., T. L. Killeen, J. P. Thayer, G. Hernandez, C. R. Tschan, and J.-J. Ponthieu, Circulation of the polar thermosphere during geomagnetically quiet and active times as observed by Dynamics Explorer 2, J. Geophys. Res., 92, 10,133-10,139, 1987.

Nishida, A., Average structure and storm-time change of the polar topside ionosphere at sunspot minimum, J. Geophys. Res., 72, 6051$6061,1967$.
Rich, F. J. and W. F. Denig, The major magnetic storm of March 13-14, 1989 and associated ionospheric effects, Can. J. Phys., 70, 510-525, 1992.

Rishbeth, H., F-region storms and thermospheric circulation, J. Atmos. Terr. Phys., 37, 1055-1064, 1975.

Sato, T., and K. L. Chan, Storm-time variations of the electron concentration in the polar topside ionosphere, J. Geophys. Res., 74, 2208-2216, 1969.

Schunk, R. W., A mathematical model of the middle and high latitude ionosphere, Pure Appl. Geophys., 127, 255-303, 1988.

Schunk, R. W., and J. J. Sojka, Ion temperature variations in the daytime high-latitude $F$ region, J. Geophys. Res., 87, 5169-5183, 1982a.

Schunk, R. W., and J. J. Sojka, Ionospheric hot spot at high latitudes, Geophys. Res. Lett., 9, 1045-1048, 1982 b.

Schunk, R. W., and J. C. G. Walker, Theoretical ion densities in the lower ionosphere, Planet. Space Sci., 21, 1875-1896, 1973.

Schunk, R. W., J. J. Sojka, and M. D. Bowline, Theoretical study of the electron temperature in the high-latitude ionosphere for solar maximum and winter conditions, J. Geophys. Res., 91, 12,04112,054, 1986.

Sojka, J. J., Global scale, physical models of the $F$ region ionosphere, Rev. Geophys., 27, 371-403, 1989.

Sojka, J. J., and R. W. Schunk, A theoretical study of the high latitude $F$ region's response to magnetospheric storm inputs, J. Geophys. Res., $88,2112-2122,1983$.

Sojka, J. J., and R. W. Schunk, A theoretical $F$ region study of ion composition and temperature variations in response to magnetospheric storm inputs, J. Geophys. Res., 89, 2348-2358, 1984.

Sojka, J. J., W. J. Raitt, and R. W. Schunk, Theoretical predictions for ion composition in the high-latitude winter $F$-region for solar minimum and low geomagnetic activity, J. Geophys. Res., 86, 22062216, 1981a.

Sojka, J. J., W. J. Raitt, and R. W. Schunk, Plasma density features associated with strong convection in the winter high-latitude $F$ region, J. Geophys. Res., 86, 6908-6916, 1981 b.

Sojka, J. J., W. J. Raitt, and R. W. Schunk, Effect of displaced geomagnetic and geographic poles on high-latitude plasma convection and ionospheric depletions, J. Geophys. Res., 84, 59435951, 1979.

Sojka, J. J., R. W. Schunk, and W. J. Raitt, Seasonal variations of the high-latitude $F$ region for strong convection, J. Geophys. Res., 87, 187-198, 1982.

Titheridge, J. E., Determination of ionospheric electron content from the Faraday rotation of geostationary satellite signals, Planet. Space Sci., 20, 353-359, 1972.

Tsurutani, B. T., W. D. Gonzalez, F. Tang, and Y. T. Lee, Great magnetic storms, Geophys. Res. Lett., 19, 73-76, 1992.

Weimer, D. R., L. A. Reinleitner, J. R. Kan, L. Zhu, and S.-I. Akasofu, Saturation of the auroral electrojet current and the polar cap potential, J. Geophys. Res., 95, 18,981-18,987, 1990.

W. F. Denig, PL/GPSP, Phillips Laboratory AFMC, 29 Randolf Road, Hanscom Air Force Base, MA 01731-3010.

R. W. Schunk and J. J. Sojka, Center for Atmospheric and Space Sciences, Utah State University, Logan, UT 84322-4405.

(Received November 15, 1993; revised May 16, 1994; accepted July 1, 1994.) 